\title{
Long Term Reform and the Banking Crisis
}

\author{
Jacques Melitz
}

Published online: 11 December 2009

(C) The Author(s) 2009. This article is published with open access at Springerlink.com

Keywords Banking crisis $\cdot$ Monetary policy

\section{JEL Classification E58 - G21}

Once we emerge from the current world recession, we will need to address the flaws in the present regulatory framework that permitted the banking crisis to assume the enormous proportions that it has. The question is how far we need to go in tightening regulation in order to correct for the insufficient safeguards against macroprudential risks that exist today. On this issue, we face an important dilemma. To regulate finance too much is to assure a permanent sub-optimal allocation of risks. It means to proceed to a situation where a large fraction of the population will need to forego a steady flow of utilities in their lifetime because of avoidable and socially inefficient credit rationing and excessive interest rates. On the other hand, to fall short of adequate regulation means to face a recurrence of the sort of collapse of finance and deep recession to which we are subject today. But while there is a fundamental choice to be made, so far as I can see, current professional discussion can be summoned on either side. This point will be the focus of my remarks.

Let me begin with the case for light regulation. A basic reason for a light regulatory response to the present difficulties is that some of the financial innovations of recent decades have important merits. This is true, in particular, of the securitization of real estate loans. Many regional lenders have inadequate opportunities to diversify the property risks in their region. Residents of other 
regions, possibly of other countries, may be in a better position to diversify these risks. In addition, and very significantly, based on many analyses of the problem, the flaws that led to the present crisis were so foolish and so easily reparable that modest changes would suffice. (1) There was a lot of ignorance of the facts. We did not know where the risk lay. In the case of tranching, we often did not know who bore the equity tranche. The parent financial organizations evidently ignored the scale of the activities of the conduits and structured financial vehicles that they had launched. (2) Banks were allowed not to book their contingent liabilities (through special conduits and structured investment vehicles) and to make no provisions against them. (3) There was excessively narrow application of fair value accounting to determine the capital of financial firms without adequate attention to the length of term of the firms' liabilities - that is, whether the firms needed to rely on the assets in question in order to finance claims over the next month or over the next five or ten years.

These are mind-boggling flaws. But they are also reparable without gravely limiting the freedom of action of financial firms in the future (though not merely by improving information, as some might pretend, because of the macroprudential issues involved and the role of coordination). ${ }^{1}$ On this view of the matter, it would suffice to engage in a number of moderate actions: to extend existing capital requirements, make more sophisticated application of the requirements, adopt some added flexibility in the requirements, make some modest reform of the rules, improve accounting, increase public information, adopt better publicity, engage in better supervision and more enforcement of the rules. Maybe a bit more would be advisable. There would be a case for outlawing some of the market innovations of recent years. For example, we might wish to forbid the derivatives of recent years that served no other social purpose than to get around the Basel I capital requirements. We might also wish to deny financial firms the ability to use inhouse models of risk to determine their own capital requirements, as became possible under Basel II. But the case for the sort of modifications of the current system that I have mentioned should not be allowed to confuse the issues and serve as justification for a general overhaul of the system.

On the opposite view, the reforms I have mentioned will not do. The macroprudential risks that were unleashed through securitization of mortgages and the innovations that allowed the financial sector to create credit without fresh funding through new issues of debt or equity from the outside are too great. These novelties permitted highly correlated housing market and equity market bubbles to go too far. Such correlated bubbles in housing and equities are inherent and likely to recur in the future. The prospect of future housing bubbles is an especially worrying one because housing represents such a huge percentage of an important proportion of people's wealth (as a result of the strong and widespread desire for individual home ownership in order to avoid another sort of non-diversifiable risk: namely, repeated compulsory changes of residence, especially at advanced age). Because of the strength of the prospects of correlated housing market and equity market bubbles in the future, we must limit the ability of financial firms to contribute to the twin

\footnotetext{
${ }^{1}$ On this parenthetical note, see, in particular, the illuminating "commentary" by Holmström (2009).
} 
bubbles. This calls for measures that radically interfere with the financial innovations of the last dozen years or more. The required measures mean severely limiting the securitization of mortgages, limiting second mortgages, restoring a strong legal distinction between investment and commercial banks, and forbidding or severely limiting short-term financing of own investments by all financial firms except commercial banks. It means basically turning back the clock to return to a situation in finance similar to the one we knew in the early eighties.

Quite significantly, according to this last position, the problems of oversight, misinformation and poor application of prudential rules that I cited in favor of a light reform agenda merely hastened the arrival of the present world crisis. They did not produce it. Paradoxically, these problems might even have helped. Had the errors not taken place, had the housing and equity bubbles therefore been more moderate, the bubbles would have lasted longer, and then they might have attained a larger size before they finally burst. Consequently, the painful reallocation of resources that we face today would have been even greater when it came. In the run up to the eruption of the crisis, more bad mortgage loans would have taken place; these would have been held more widely internationally; and the excessive absorption of resources in finance that we know today, as a result of horrible price signals, would have gone further. Ironically, it is also arguable on this position that the errors of monetary policy in the Greenspan years improved matters by causing the bubbles to grow faster and therefore to burst sooner.

I believe that we currently do not know which of these two positions is right.

Open Access This article is distributed under the terms of the Creative Commons Attribution Noncommercial License which permits any noncommercial use, distribution, and reproduction in any medium, provided the original author(s) and source are credited.

\section{Reference}

Holmström B (2009) Commentary: The panic of 2007. Federal Reserve Bank of Kansas, Maintaining stability in changing financial system (Symposium, August 21-23, 2008), 263-273 